\title{
REVIEW
}

\section{Surgical management of ambiguous genitalia}

\section{Rangecroft, on behalf of the British Association of Paediatric Surgeons Working Party on the Surgical Management of Children Born with Ambiguous Genitalia}

The surgical management of children born with ambiguous genitalia has always been difficult, subject to evolving attitudes and techniques, and at times controversial. Standard protocols have stressed the need for early diagnosis, gender assignment, and appropriate surgery in infancy.' In recent years some authors, backed by patient support groups, have claimed that such surgery is damaging or mutilating and, as it is essentially cosmetic, should not be performed until the fully informed consent of the patient could be obtained-that is, when the child becomes "Gillick competent". ${ }^{2-4}$ There are, however, so many specific issues related to the different diagnostic groups that such a policy would seem to be too prescriptive.

See end of article for authors' affiliations

Correspondence to: Mr L Rangecroft, Consultan Paediatric

Surgeon/Urologist,

Department of Paediatric

Surgery, The Royal Victoria

Infirmary, Newcastle upon

Tyne NEl 4LP, UK;

Laurence.rangecroft@

nuth.northy.nhs.uk

Accepted

21 November 2002 $\mathrm{n}$ view of the comparative rarity and complex issues involved in treating these children, we would unreservedly recommend their early referral to the nearest regional centre for both immediate and continuing management by a multidisciplinary team. No assignment of gender should be made prior to referral. The disciplines involved must include appropriately trained paediatric surgeons and/or paediatric urologists, neonatologists, and paediatric endocrinologists and their specialist nurses/support workers, geneticists, biochemists, psychologists, and gynaecologists. Psychological support for the child/ adolescent and family should be well integrated with medical input, easily accessible at the time of need, and provided by, or in consultation with, a specialised service. These multidisciplinary teams and clinics are an obvious and important resource for training and research, and, in particular, follow up studies. While this multidisciplinary approach is the ideal it is appreciated that not all regional centres are fully funded for every discipline and particularly for psychological support and some laboratory/genetic services.

While there is likely to be continuing pressure from parents for early corrective surgery, fully informed consent for such procedures would require them to be aware of the possibility of non-operative management with psychological support for the child and family.

\section{CONGENITAL ADRENAL HYPERPLASIA (CAH)}

$\mathrm{CAH}$ produces virilisation of the female fetus and forms the largest single diagnostic group of children presenting at birth with ambiguous genitalia in the United Kingdom. The degree of virilisation varies widely.
Although some of these girls may opt to change gender in later life, published reports to date suggest that the incidence is low and does not, of itself, constitute a strong indication for delaying feminising genitoplasty until adolescence or beyond. ${ }^{5}$ Rarely the diagnosis may be missed and a severely virilised 46 XX individual may be raised as a boy. Assignment of gender has to be on an individual basis, and the decision may need to include cultural considerations.

The two essential elements of feminising genitoplasty are clitoral reduction/recession and vaginoplasty. While the operation of clitoral shaft resection with preservation of the glans on its neurovascular bundles seems logical, and is probably an advance on total clitorectomy or clitoral recession, there is no evidence that the retained glans functions well in sexual/orgasmic terms. Indeed there is some emerging evidence to the contrary. ${ }^{7}$ Further revisional procedures in adolescence are common and may do further sensory damage. Surgeons and parents need to be fully aware that this is the case before proceeding with this irreversible procedure, and that there is a strong case for no clitoral surgery at all in lesser degrees of clitoromegaly.

The ease with which vaginoplasty can be performed at any age depends on the length of the common urogenital sinus. The few long term follow up studies currently available suggest that the majority of girls will require some, and often major, revisional surgery for vaginal or introital stenosis in adolescence. ${ }^{78}$ Since early vaginoplasty confers no obvious benefit in a young girl, there would seem to be a strong case for delaying it until the onset of menstruation possibly makes it mandatory. The advent of more recent techniques for coping with the high vagina, such as the Passerini-Glazel procedure, ${ }^{9}$ would seem unlikely to alter the outcome as regards revisional surgery significantly. Individual surgeons may feel that vaginoplasty is still warranted in the low, and therefore more straightforward cases, although again it confers no obvious benefit to the child or her parents. The occasional patient with a urogenital sinus complicated by urinary stasis and/or infection may require an early surgical procedure. Furthermore, even when the consequences of early surgery have been explained to the parents there may still be some who will be unable to cope with the virilisation of their child. There is, as yet, no evidence to show what effect the rearing of a severely virilised female will have on the long term outcome. Under these circumstances this group should not be denied what is currently standard treatment - that is, early feminising surgery. Again, this should only be performed with fully informed consent. 


\section{COMPLETE ANDROGEN INSENSITIVITY SYNDROME (CAIS)}

These individuals have a $46 \mathrm{XY}$ genotype, testes which are intra-abdominal or contained in inguinal herniae, and no internal female genitalia. The phenotype, however, is of a normal female although the vagina is invariably short and may be severely so. Few will be diagnosed in the neonatal period, but some will present early with hernia and raise the issue of early gonadectomy. All will be raised as girls and early gender assignment is not usually an issue. Later hormonal virilisation is not, of course, possible.

\section{Timing of gonadectomy}

This remains controversial and adequate data on which to base recommendations are scarce. ${ }^{10}$ The foremost concern is the potential for malignant change and the age when this may occur. It has been argued that any such risk favours early gonadectomy, but set against this is the possibility that bone maturation and body development in puberty may be better if mediated by the gradual and early emergence of endogenous sex steroids (aromatisation of testosterone to oestrodial occurs normally in CAIS) compared to the necessarily somewhat rigid regimens of exogenous administration. While one report has suggested an association between greater bone mineral density and late gonadectomy there is insufficient evidence to recommend it on that ground alone. ${ }^{11}$

In relation to malignant change a comprehensive review in 1987 quantified the risk at 2-5\% in CAIS patients over 25 years of age, and the risk was deemed "small" prior to that age. ${ }^{12}$ In a study of 17 post-pubertal CAIS patients from Venezuela, no malignant change was found. ${ }^{13}$

There are three possible options:

- Early gonadectomy, particularly if they are contained in an inguinal hernia sac, or there are parental concerns over malignant change, or difficulty in accepting a female phenotype while testicular tissue is present.

- Late gonadectomy performed as soon as puberty has been completed.

- No gonadectomy in patients who are as well informed as possible of the potential malignancy risks. Follow up of any such individuals would need to be assiduous and long term.

It has been suggested that cryopreservation of gonadal tissue should be undertaken in those patients with AIS undergoing gonadectomy with a view to future fertility treatment. While the techniques of freezing testicular tissue and reusing it are now established, the ethical and moral issues surrounding these techniques are not clear, even in the non-intersex group. There is currently a multidisciplinary working party convened by the British Fertility Society looking at the issues surrounding cryopreservation, and until further information is available, this committee does not recommend cryopreservation on a routine basis.

\section{Vaginal lengthening}

Since there is no prospect of menstruation in these individuals, and orgasm should be possible in all, "satisfactory" intercourse in relation to penetration is the only physical indication for trying to increase vaginal length. Various methods of self dilation are available and seem the preferred option, with reported success rates of $85-90 \% .{ }^{14}$ The Vecchietti procedure ${ }^{15}$ is favoured by some patients but unavailable in the UK, due to non-approval of the bougie device, and there is anecdotal evidence that the rapid ( $2-3$ weeks) elongation produced by this manoeuvre leaves the vagina with insufficient support and can lead to prolapse. If total vaginal replacement is required, sigmoid colon or ileum are probably the best options, but both skin and amnion grafts have their advocates.

\section{THE SEVERELY UNDERVIRILISED GENETIC MALE}

Conditions producing this state include partial androgen insensitivity syndrome, 5- $\alpha$ reductase deficiency, testicular regression syndrome, and severe hypospadias. Historically many of these genetically $46 \mathrm{XY}$ individuals have either been raised as females or surgially assigned as such (including castration), because of what was deemed "surgically possible". Evidence for the effects of testosterone on the fetal brain, and subsequent post-pubertal gender identity in humans is somewhat equivocal. ${ }^{16}$ However, studies from areas such as the Dominican Republic and Papua New Guinea on "untreated" 5- $\alpha$ reductase patients have shown a strong tendency to virilise at puberty and almost $100 \%$ assumption of the male gender identity/role. ${ }^{17}$ Furthermore, follow up studies by Reilly and Woodhouse on adult males with micropenis (defined as less than 2.5 SD below the mean stretched length for age or stage of sexual development) have shown surprisingly good outcomes in terms of sexual function. ${ }^{18}$

Assignment of such individuals to the female gender by surgery should only be undertaken with considerable caution and following full multidisciplinary investigation and counselling of the parents.

\section{TRUE HERMAPHRODITES/MIXED GONADAL DYSGENESIS}

Most of the issues in relation to these rare individuals have already been covered by the above, but there is unequivocal evidence of a greater risk of malignant change in dysgenetic and streak gonads. ${ }^{19}{ }^{20}$ Streak gonads and any gonad inappropriate to the sex of rearing should, therefore, be removed and any retained testis should be placed in a palpable position for easier surveillance.

Members of Working Party: Dr C Brain, Consultant Paediatric Endocrinologist, Great Ormond Street Hospital, London; Miss S Creighton, Consultant Gynaecologist, University College London Hospitals, London; Dr D Di Ceglie, Consultant Child and Adolescent Psychiatrist, The Portman Clinic, London; Mr P Malone, Consultant Paediatric Urologist, Southampton General Hospital, Southampton; Dr A Ogilvy-Stuart, Consultant Neonatalologist, Addenbrooke's Hospital, Cambridge; Mr L Rangecroft (Chair), Consultant Paediatric Urologist,

Royal Victoria Infirmary, Newcastle upon Tyne; Mr R Turnock, Consultant Paediatric Surgeon, Alder Hey Children's Hospital, Liverpool

\section{REFERENCES}

American Academy of Pediatrics. Evaluation of the newborn with developmental anomalies of the external genitalia. Pediatrics 2000; 106:138-42

2 Dreger AD. "Ambiguous sex" ... or ambivalent medicine? Ethical issues in the medical treatment of intersexuality. Hastings Center Report, Vol. 28 , 1998:24-5.

3 Kipnis K, Diamond M. Pediatric ethics and the surgical assignment of sex. J Clin Ethics 1998;9:398-410

4 BAPS Ethical Committee. Gender assignment surgery in children. Ethical position for clinicians. 2000, www.baps.org.uk.

5 Ehrhardt AA, Meyer-Bahlburg HFL. Effects of prenatal sex hormones on gender related behavior. Science 1981;211:1312-18.

6 Mosley M, Bidder R, Hughes I. Sex role behaviour and self-image in young patients with congenital adrenal hyperplasia. Br J Sexual Med 1989; 16:72-5.

7 Creighton SM, Minto CL, Steele SJ. Objective cosmetic and anatomical outcomes at adolescence of feminising surgery for ambiguous genitalia done in childhood. Lancet 2001;358:124-5.

8 Alizai NK, Thomas DFM, Lilford RJ, et al. Feminising genitoplasty for congenital adrenal hyperplasia: what happens at puberty. $J$ Urol 1999;161:1588-91.

9 Passerini-Glazel G. A new 1-stage procedure for clitovaginoplasty in severely masculinised female pseudohermaphrodites. J Urol 1989; 142:565

10 Viner RM, Teoh Y, Williams DM, et al. Androgen insensitivity syndrome: a survey of diagnostic procedures and management in the UK. Arch Dis Child 1997;77:305-9. 
11 Soule SG, Conway G, Prelevic GM, et al. Osteopenia as a feature of the androgen insensitivity syndrome. Clin Endocrin (Oxf) 1995;43:671-5.

12 Verp MS, Simpson JL. Abnormal sexual differentiation and neoplasia Canc Genet Cytogenet 1987;25:191-218.

13 Alvarez-Nava F, Gonzalez S, Soto $M$, et al. Complete androgen insensitivity syndrome: clinical and anatomopathological findings in 23 patients. Genet Counselling 1997;8:7-12.

14 Costa EM, Mendonca BB, Inacio M, et al. Management of ambiguous genitalia in pseudohermaphrodites: new perspectives on vaginal dilation. Fertil Steril 1997:67:229-32.

15 Borruto F, Chasen ST, Chervenak FA, et al. The Vecchietti procedure for surgical treatment of vaginal agenesis: comparison of laparoscopy and laparotomy. Int J Gynecol Obstet 1999;64:153-8.
16 Meyer-Bahlburg HFL. Commentary: Gender assignment and reassignment in $46, X Y$ pseudohermaphroditism and related conditions. J Clin Endocrinol Metab 1999;84:3455-8.

17 Imperato-McGinley J, Miller M, Wilson JD, et al. A cluster of male pseudohermaphrodites with 5- $\alpha$ reductase deficiency in Papua New Guinea. Clin Endocrinol 1991;34:293-8.

18 Reilly JM, Woodhouse CRJ. Small penis and male sexual role. J Urol 1989;142:569-71.

19 Manuel M, Katayama KP, Jones HW. The age of occurrence of gonadal tumors in intersex patients with a Y chromosome. Am J Obstet Gynecol 1976;124:293-300.

20 Savage MO, Lowe DG. Gonadal neoplasia and abnormal sexual differentiation. Clin Endocrinol 1990;32:519-33.

\section{IMAGES IN PAEDIATRICS.}

\section{Occult intraspinal glass injury}

njuries due to glass are common in children. ${ }^{1}$ We present the case of a 4 year old female who fell into a glass cabinet at home. A relative promptly removed a piece of glass from the child's left flank.

The child attended her district emergency department. She was cardiovascularly stable, with a clear chest, soft abdomen, and no neurological deficit. A $6 \mathrm{~cm}$ laceration to the left loin was noted. Abdominal and chest $x$ ray examinations revealed a glass fragment lying at the T12 level of the vertebral column (fig l). Computed tomography showed a $4 \mathrm{~cm}$ shard of glass entering the $\mathrm{Tl} / 2 / \mathrm{Ll}$ intervertebral foramen and displacing the spinal cord (fig 2). There was a left renal haematoma with normal urography.

The patient was transferred with spinal precautions to our unit, and wound exploration undertaken by general and neurosurgical teams. The intraspinal shard of glass was removed and a left renal capsular laceration identified. The child recovered uneventfully without neurological sequelae.

This case emphasises the need for meticulous assessment of penetrating glass injuries. Ideally, protruding fragments should not be removed prior to imaging. Residual shards should always be suspected. Fortunately, however, glass injuries to the spine remain extremely rare in children.

S L Almond, E C Jesudason, P D Losty

Department of Paediatric Surgery, Alder Hey Children's Hospital, Liverpool

C L Malluci

Department of Paediatric Neurosurgery, Alder Hey Children's Hospital

Correspondence to: Miss S Almond, University of Liverpool, Institute of Child Health, Alder Hey Children's Hospital, Eaton Road, Liverpool L12 2AP, UK; salmond@liv.ac.uk

\section{References}

1 Bell D. Two hundred glass injuries. Arch Dis Child 1984;59:672-3.

2 Vadasz AG, Torres CF, Chang JK. Accidental penetrating cervical cord injury in a young child. Pediatr Emerg Care 1996;12:428-31.

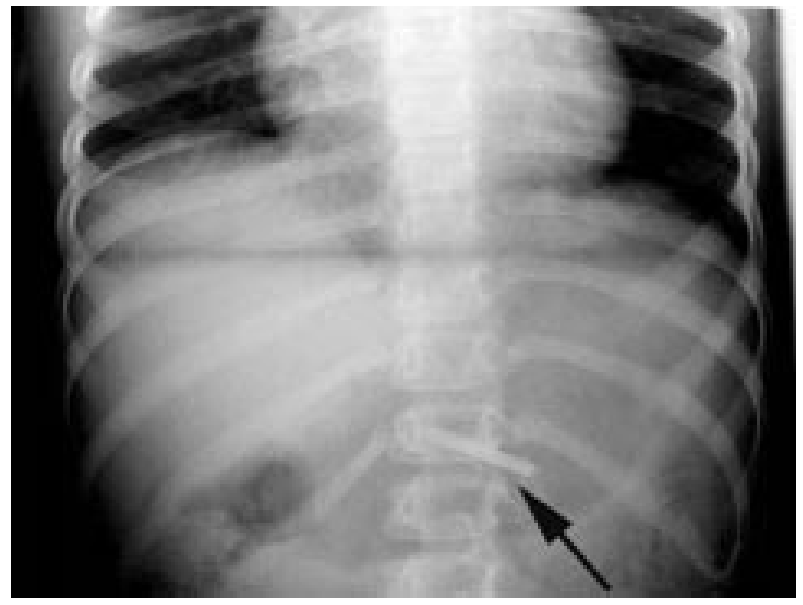

Figure 1 Plain radiograph showing the lower chest and upper abdomen. The retained glass fragment is clearly visible projected over the T1 2 vertebra.

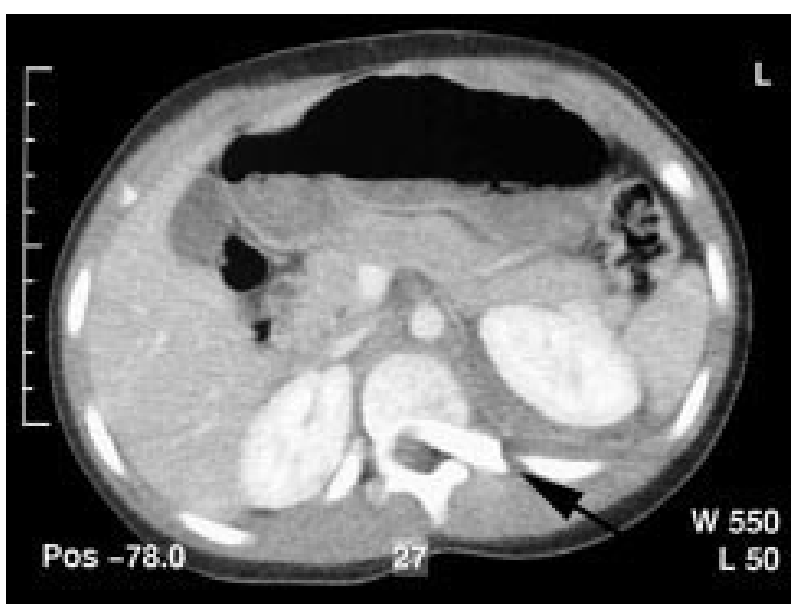

Figure 2 Computed tomographic scan showing a transverse section at T12. The glass fragment is seen entering the spinal cana at this level. 